\title{
The future of forensic science education
}

\author{
J.P. Cassella, A. Williams and P.D. Maskell
}

This is the accepted manuscript of the book chapter:

Cassella, J.P., Williams, A. and Maskell, P.D. 2017. The future of forensic science education. In: A. Williams, J.P.

Cassella and P.D. Maskell, eds. Forensic science education and training: a tool-kit for lecturers and practitioner trainers. Chichester: Wiley. 2017, pp.301-310.

It has been published in final form at doi: http://dx.doi.org/10.1002/9781118689196.ch18

Published version (C) 2017 John Wiley \& Sons http://eu.wiley.com/WileyCDA/WileyTitle/ productCd-1118689232.html

This chapter may be used for non-commercial purposes in accordance with the Wiley Terms and Conditions for SelfArchiving. 


\section{Chapter 18 - The Future of Forensic Science Education}

Cassella, J P. Williams, A. and Maskell, P.D.

\section{Abstract}

The education and training landscape of Forensic Science has changed greatly in the last decade. This is due to many factors, ranging from Government level changes (closure of the FSS in the UK, the National Academy of Sciences report in the USA, the UK Silverman report and similar reports and of course worldwide scientific developments such as DNA 17 and DNA 24 etc).

Changes have occurred within the University sector and also from the expectation of students at university and these have required developments in the number of institutions providing such courses and how they are taught and assessed. The expectation of the industry - the Criminal Justice system, the Police, the scientific community and indeed the pubic have all had an effect in shaping the modern $21^{\text {st }}$ Century Forensic Science/ Policing Science courses at HEIs. These changes have required the modern forensic educationalist to upskill beyond their subject specific skills to cope with new technology, the ongoing developments in teaching-accreditation, competency testing and ISO standardisation of the forensic industry. The wider education and transferrable skills teaching allowing graduates to work in a more generalised scientific industry such as chemistry should not be forgotten. Whilst there was, for a time, experienced academics from other subject specialisms (chemistry, biology etc.) who in the early 'naughties' retrained into forensic science teaching or indeed those practitioners who came from the closed Forensic Science Service into teaching, individuals with these skill sets have been mined-out and so this text has been designed for the new lecturer or those wishing to reinforce their existing skills using the toolkit of experiences and ideas shared here. At the least, it should engender a starting point for discussion about what can and should be developed in the classroom to teach the skills making graduates fit for modern forensics-policing. 
The technological drive towards a greater degree of automation of forensic science techniques and the use of new technologies have seen the trend toward smaller workforces, making it challenging for forensic graduates to find and keep employment and progress their careers in the forensic science sector and some of the aspects considered throughout this text reflect the need for developing these transferrable skills into other allied specialisms.

The questioning of forensic science in the $21^{\text {st }}$ Century has undeniably revealed itself in the growing application of the Frye rule initially, and later in the application of the Daubert standard. In the Courts today, questions about the validity of forensic laboratory procedures are raised on an ever-more frequent basis and so what is taught is the classroom must reflect this need for robust, unbiased and statistically supported reporting.

\section{Introduction}

The forensic science education sector has the job to produce the next generation of researchers, practitioners and educators. There is no lack of provision of forensic courses in the UK and the USA with the sector developing at an unparalleled rate over the last 20 years. (Quarino and Brettell, 2009; Rankin et al. 2012). In the USA the American Academy of Forensic Sciences website (www.aafs.org) revealed over 100 forensic science programs leading to a Bachelor's degree. In addition, over 50 programs leading to a Master's level degree in forensic science or a related discipline in the USA alone are listed. In the UK, UCAS states that there are 87 providers of degree courses containing the word 'forensic' in the title available for a 2017 start. This rapid expansion of teaching courses has been openly criticised (Rankin et al. 2012) with relevance, suitability and quality of the degree content raised as issues. Courses have suffered from a rapid growth beyond the capability of the academic and technical support staff, the existing resources and indeed existing hard structure facilities, resulting more from a financial need rather than for pedagogical motives. This has caused academic staff to have to hurriedly develop their skills in order to stay 'one step ahead' of the students. Forensic science is a discipline in which the educators have to walk a tightrope between vocational training and theoretical teaching, in order to produce graduates who carry considerable 
professional responsibility and can demonstrate consistent competence in the workplace. Also integral to the course is instilling an understanding of the statistical power of any data obtained from forensic techniques and recognition of their implications for the court. Such issues create problems for educators, who come from a range of backgrounds and perspectives, and who therefore have to align their different priorities and professional requirements with the validation mechanisms of the University. The degrees have had to simultaneously meet the requirements of academia, professional organisations and prospective employers, as well as meet the needs of a disparate and changing student body, including mature students and those that require learning support. Practitioner training also poses challenges to the trainers, from teaching 'old dogs new tricks', deconstructing entrenched processes and methodologies, to contextualising their practice for teaching and assimilation in the classroom.

This forensic science education text is the first of its kind to capture a diverse collection of literature, websites and practitioner experiences and to distil them into a helpful and meaningful toolkit and reflective aid for new academics and practitioner trainers working in today's forensic education. We have included a number of, but by no means an exhaustive range, forensic sub-disciplines. Therefore, this volume contains the collective experiences of forensic practitioners and teachers, and has been designed to offer new lecturers tools to assist in the creation and in the delivery of undergraduate and postgraduate modules and courses in forensic science. We have also aimed to offer practitioners coming into the Higher Education sector an understanding of the HE marketplace, and to facilitate a bridge between professional practice and academia to help demystify the complexities and nuances of academia and how to deliver relevant concepts in pedagogical theory. Implicit in these chapters is an understanding that up-to-date, relevant teaching must be researchled and, as much as possible, interactive. Heavy teaching loads for all academic staff and the increasing administrative requirements coupled with insufficient funding means that research can become, for some, a luxurious aspiration. It is hoped that the experiences offered by the authors in this text will inspire readers to develop research interests, take the questions out of the lecture theatre and the laboratory into research projects that they and their students can investigate and publish. It could serve as a spring board for lecturers 
to build upon their own research areas, facilitating the generation of ideas and opportunities to apply for funding, ultimately resulting in research that can impact and improve frontline forensic services and also impact on the forensic science teaching in the classroom.

This chapter will consider how we ensure and maintain quality of teaching, learning and assessment; how we manage the currency of competency in academic staff delivering their subject and how they interact with the increasing number of practitioners - both policing and forensic scientists - now working alongside them in HEIs. Also, we will explore the impact and implications of the new Teaching Exercise Frame work (TEF) and the future of the research exercise frame work (REF) for forensic science education, and consider the changing needs of employers, the prospects for graduates seeking employment with small to medium enterprises (SMEs), police and government organisations, in the changing face of public funding. We will also consider the current and future fora for wide-ranging discussions about, and dissemination of, good practice in teaching, learning and assessment in forensic science and related disciplines. A prediction of the next decade of education in light of falling student numbers, increasing University fees and reduced opportunities for funding coupled with a shrinking forensic jobs market will be considered.

\section{The Teaching Exercise Framework and the Research Exercise Framework}

Teaching Exercise Framework

The mass expansion of higher education along with the progressive introduction of fees and an ever expanding research agenda have changed the institutional priorities of UK (and indeed international) universities over the past 25 years from teaching and scholarship to research and economic innovation (Forstenzer, 2016). The aim of the incoming Teaching Excellence Framework (TEF) is to rebalance 'the relationship between teaching and research' in universities and place 'teaching at the heart of the system', by introducing a teaching quality assessment mechanism using core metrics and qualitative evidence. Universities deemed to have 'excellent' teaching will be rewarded with the opportunity to increase undergraduate fees in line 
with inflation. Therefore the newly created Teaching Excellence Framework (House of Commons, Business, Innovation and Skills Committee, 2016) will have enormous implications for teaching in the coming decade. It is increasingly reported in the news-media that it is not difficult to find students from a range of degree subjects who feel let down by their degree courses. Countless surveys have been published indicating that students don't feel they are getting value for money, while the Universities minister has been quoted as saying that the quality of teaching in higher education is "lamentable".

To help improve the situation and address these criticisms and to give applicants a better idea of what sort of teaching they can expect at university, the government will be revealing its new Teaching Excellence Framework (TEF). It's expected that the TEF will use statistics such as student satisfaction scores or the progress made by students from disadvantaged backgrounds, as well as other existing data. Universities that pass the test will be allowed to raise their fees in line with inflation. The key to its usefulness in HEIs will require the metrics to focusing on considering how well-thought-out the structure of a programme is and not on an individual teacher or module. A concern is that whilst student satisfaction scores and employability data are already available at a course-specific level, the TEF will measure institutions on a university-wide basis - which might not be that helpful.

\section{Research Exercise Framework}

The Research Excellence Framework is a UK Government-level mechanism for assessing the quality of research publications and subsequently apportioning government funding to HEIs for the coming five-year period and beyond. In order to assess research quality and focus the assessment on specific areas the REF is divided up into 'Units of Assessment' (UoA). Whilst there are Units of Assessments for traditional subjects such as Engineering, Physics and Chemistry, there is no UoA for Forensic Science, and no current plans to include one in the next REF in 2020. Forensic Science, by its very definition, utilises numerous distinct sciences and as such it may easily be included in at least 20 of the current 35 Higher Education Funding Council for England (HEFCE) 'Units of Assessment' in the Research Excellence Framework exercise conducted to assess the quality of UK research. As an analogy, chemistry uses tools 
developed in engineering, physics, computer science and mathematics. However, clearly, it would be inappropriate to submit mainstream chemistry research for scrutiny under any of the UoA relating to these other disciplines. To do so would inevitably skew the types of research conducted within chemistry so as to better fit the demands of those UoA. Also, it would fragment chemistry research teams such that the work of individual members of such teams would be examined under different units. Finally, it would mean that chemistry would be assessed out of context. It is difficult to see, for example, how high quality synthetic organic chemistry research could be rationally assessed as good quality physics - even if a chemist were asked to conduct this assessment.

Yet this is the current position that Forensic Science finds itself in and it is a widely held contention that this is damaging development in this crucial field. One consequence of this situation of pitting oranges against apples is the on-going poor success rate to receive funding through the established bodies such as Higher Education Funding Council for England and the Research Councils UK.

In recent years there have been significant national reviews and changes within the forensic industry giving forensic science a significantly higher profile specifically as a distinct subject. This has led to a chink of light in forensic research with the funding by the Leverhulme Trust of the Leverhulme Centre for Forensic Science at Dundee University for 10 years.

This suggests that high quality forensic research, published in journals with a high impact factor will have little or no contribution to the financial outcome of the REF exercise. This lowers the perceived value of forensic research, both by Universities delivering forensic science, the grant awarding bodies, and the academic community themselves. In the current situation, academics find their research having to be submitted as part of the REF under the auspices of other Units of Assessment, which may not necessarily be the most appropriate. For example, forensic anthropology articles have been included in the Biological Sciences UoA. Researchers should consider, early in the research process, how their research will fit into existing UoAs, rather than retrospectively attempting to shoehorn their work into this current REF structure. However, the boundaries and definitions of the UoAs for the upcoming 2020 REF are yet to be 
published. It is still extremely unlikely that Forensic Science will have its own UoA.

The global issue of research opportunities and research funding is nowhere more obviously suffering than in the arena of forensic science. The impact of assisting to solve crime and facilitate an early and secure conviction (or release of the innocent) is absolute. Despite the lack of a UoA for forensic science in the REF, there is still therefore a societal need to conduct research. This is driven by the requirement for robust data to present to the courts, as well as scientific development and indeed confirmation of new techniques and processes. Whilst securing research funding is challenging, the opportunity exists to use postgraduate and indeed undergraduate students as researchers, as part of their development and assessment during their degree program. Quarino and Brettell (2009) comment that the development of forensic science doctoral programs would greatly benefit the profession. Doctoral level research can be performed not only on the application of existing technologies to forensic science problems, but on addressing those aspects of forensic science that have been widely anecdotally accepted but not rigorously scientifically proven, such as bite mark and shoe wear analysis. For instance, greatly needed research into the development of statistical models to unequivocally prove the uniqueness of fingerprints, handwriting, or footprint evidence can be facilitated within doctoral programs. The validity of long-held concepts such as the Locard's Exchange Principle could also be empirically examined. The development of doctoral programs may also influence public sources of funding and to provide lobbying power and hence more financial support to forensic science research.

Whilst ostensibly the REF may be seen as a limiting factor to teaching delivery, as it diverts staff attention and effort from the classroom and student support, it drives the creation of new knowledge for publication, and will ultimately benefit teaching and learning.

\section{Accreditation of Forensic Science Providers}

One aspect that will define forensic practice and education over the next decade and beyond is accreditation of not only forensic sciences education but also of practitioners and forensic science providers. 
The UK Forensic Science Regulators recommendation to the industry is for providers of forensic services to obtain United Kingdom Accreditation Service (UKAS) accreditation so that the end-user of their information may be absolutely confident of the information supplied to the Criminal Justice System. The two most common accreditation standards are ISO17025 (for testing laboratories i.e. DNA testing and Toxicology testing) and ISO17020 for "inspection bodies" such as searching crime scene and post-mortem investigations. Although there have been concerns, such as at a meeting of forensic practitioners and legal professionals at Leeds University School of Law in 2012, that "accreditation will help establish mutual trust in the validity of the basic analytic methods used. However, accreditation does not state which method to use, only that the method used has to be suitable for its purpose." (NUCFS, 2012). The nature of the ISO accreditation addresses the possible variability that might exist between forensic science providers as a part of the requirement for validation is that accredited providers take part in external proficiency testing schemes that allow comparisons between providers and require the providers to undertake corrective actions in the event of the expected deviation from the expected result. An up-to-date list of accredited forces and private companies can be sourced via the UKAS website (www.UKAS.org).

\section{Accreditation of Academic Forensic Courses}

The academic content, nature of delivery, incorporation of expertise from practitioners and relevance to real world forensic science has developed within UK HEIs. Central to this has been the Quality Assurance mechanisms in place in UK HEIs, the involvement of the University subject-specific External Examiner system and of course the Chartered Society of Forensic Sciences (CSoFS) accreditation processes. The CSoFS accreditation service is for those Higher Education Institutions delivering courses that contain forensic components. The courses intended for accreditation are normally at Bachelors' degree with Honours or indeed a post-graduate qualification such as a taught Masters' degree with forensic elements. The CSoFS scheme establishes and maintains standards of education within forensic science and involves major employers and professional interests. Accreditation is based upon a series of 
'Component Standards'. The standards address specific areas of forensic practice and are intended to augment underlying scientific knowledge of the forensic components. The component standards form a substantial part of the Quality Assurance Agency (QAA) benchmark statement for forensic science. All forensic courses have a core Interpretation, Evaluation \& Presentation of Evidence (IEPE) Component Standard. General forensic science degrees are covered by two further component standards; Crime Scene Investigation and Laboratory Analysis. Additional specialist areas have their own component standards in addition to the IEPE. The National Occupational Standards (NOSs) are applicable to various employment roles whilst the CSoFS Component Standards address the educational and development needs pertaining to relevant roles in the forensic field. The outcome of this process has been to bring into line the basic elements of the delivery and content to ensure appropriateness and currency for the profession.

The quality of HEI forensic science courses has undergone some scrutiny in the media but the work reported by Welsh and Hannish (2011) demonstrated that, in the UK, the Quality Assurance Agency (QAA) which safeguards the public interest in sound standards of Higher Education qualifications and informs and encourages continuous improvement in the management of the quality of Higher Education, is 'satisfied'. The QAA conducts institutional audits of Higher Education Institutions. The QAA has reported 'broad confidence' in the soundness of all of the universities' that offer Forensic Science and Crime Scene degrees in the UK, current and likely future management of the quality of its academic programs and the academic standards of its awards; broad confidence is the highest confidence judgment the QAA can give.

\section{Accreditation of Forensic Science Practitioners}

There are currently two routes for the "accreditation" of forensic practitioners in the UK that of accreditation of the practitioner by their professional body (for example Forensic Pathologists and Forensic Anthropologists) and also by the Chartered Society of Forensic Science (CSoFS). The CSoFS accreditation model has been designed for Small to Medium Enterprises and sole traders who do not currently have formal accreditation to the appropriate ISO standards. The assessment of competence is a direct route to being 
held on the CSoFS's formal register providing that other necessary criteria are met. The ongoing development of competencies in a range of forensic disciplines is an iterative development and the CSoFS continues to announce assessment events for different disciplines on the Society's website. Elements of the assessment process are be externally endorsed by various UK universities depending on the discipline involved. The register of competent companies and forensic science providers is intended to provide confidence to the public and assurance to the Courts that the competent presentation of expert evidence is an important part of an individual's role.

The Court will, quite rightly, continue to have the final say with regards who can present evidence, whether accredited or not - and if they meet the reliability tests for an Expert witness. Barristers may well consider the reliability criteria have an input in this area before engaging with an expert.

One issue that pervades current forensic education within HEIs is the separation that still exists between education and the practitioner. Whilst the ad hoc systems have facilitated some involvement and innovative educational practices for those HEIs that have formed a liaison with their regional Police service and forensic providers, there is no national or structured systematic activity across institutions and organisations. This is becoming increasingly more important in order to ensure graduates who are fit for practice. Issues such as competency and accreditation are sporadic within the industry and one mechanism to drive forward a consistent approach in the UK will be to embed these practices into the education of undergraduates, so that they expect them to be part of their eventual employment.

\section{Employers in the next decade}

Currently, there are a number of private forensic service providers who function through tendering for services from police forces around the UK. The volume and scope of these tenders has changed significantly since the closure of the FSS, who previously did the majority of the work. The closure of the FSS means that there are fewer forensic jobs available for graduates. Forensic science graduates are therefore highly reliant on the 'transferable skills' gained through their degrees. An outcome of this will undoubtedly be 
a reduced need for forensic graduates and potentially the demise of forensic science degrees in some Universities.

The future of Forensic Science in Higher Education is challenging for a number of reasons. The national level changes in the forensic and policing landscapes in the last few years is testament to how rapidly situations can change. The closure of the UK Forensic Science Service, the increase in the numbers of independent forensic companies, and the developing role of the UK Forensic Regulator, are all evidence of these profound changes. Thus far, there have been no high profile miscarriages of justice reported in the media, however such an event would undoubtedly send ripples for a requirement of immediate change through the industry just as they have done previously. The UK based New Scientist magazine (Geddes, 2012) reported that the 75 percent of UK forensic scientists who responded to a New Scientist survey believed that the closure of the UK's Forensic Science Service (FSS) would lead to an increase in miscarriages of justice. Most forensic scientists also believed that switching to private and in-house police labs would reduce impartiality in interpretation, and therefore accuracy, of evidence. However, 78 percent of forensic scientists surveyed did not feel confident that the regulator has sufficient resources to ensure that standards are adequate and consistent between providers.

Quarino and Brettell (2009) state that it "stands to reason" that professionals who have academically studied forensic science may be more inclined to view an employment position as a "career" rather than simply as a "job". These individuals may be open to engage in opportunities beyond their typical job duties such as research and become actively involved in professional organisations or policy groups. A better-educated workforce may allow laboratories to go beyond task completion and become more focused on problem solving, but clearly this will be based upon and balanced by the economic pressures of a profit-oriented company.

Whilst it has been suggested in many forms by many different stakeholders that forensic science education within Higher Education Institutions had a shelf-life and that, for the most part, programs were of variable quality and of limited use to the practitioner industries they served (the Forensic, the Policing and the Criminal Justice System), it now appears that more than ever before those 
industries wish to have a meaningful dialogue and develop relationships with HEIs.

\section{The future of forensic science education and practitioner training}

It is clear that forensic science education in 2017 remains as challenging as it did nearly 20 years ago when the explosion of undergraduate courses occurred in the United Kingdom. In fact, with the changes in the industry, the challenges are even greater: the closure of the UK's Forensic Science service, the expectations of accreditation by the International Organisation for Standardisation (ISO) and developing quality standards and competency testing across the industry place pressures on an already stretched workforce. Public service cuts will undoubtedly continue into the next decade and clearly have an effect on the number of staff, the nature of the work undertaken and the technology that will underpin both. These industry level changes are inexorably bound up with the educational landscape. With courses already bursting at the seams with academic content, there is the expectation that the elements mentioned above should also be included and their understanding and applications assessed within degree courses if the graduates are to be fit for the modern forensic workplace and indeed the Court of Law.

There have been a number of very positive developments in terms of the nature of the educational provision. The closure of the Forensic Science Service in 2012 and the 30 year retirement rule in the police force has resulted in more former forensic scientists and former police officers now working as part of the full-time academic teams throughout UK HEIs. There are greater and indeed stronger links between the forensic and police practitioners and academia. There have been numerous UK and international conferences over the past 15 years that have facilitated networks to develop, grow and share good practice across the industry. The role of organisations such as the UK Chartered Society of Forensic Sciences, the American Academy of Forensic Sciences, and the involvement of educational bodies such as the UK based Higher Education Academy and the UK Quality Assurance Agency have all served to develop, refine and improve the quality and diversity of forensic science educational provision. The development of research frameworks still has to be 
further developed but the progress so far has allowed trickle-down of newly created research knowledge into the lecture theatre and laboratory.

The Educational and Industry Forum offers the opportunity for accredited universities, forensic suppliers, providers, other universities and stakeholders to meet and discuss current developments within the forensic arena on an annual basis.

The contribution to on-going public safety makes research, development and innovation within forensic science a key area which has been recognised by the UK Home Office Technology Strategy Board and its 'Special Interest Group in Forensic Science'. The utility of forensic science and the probity that can be achieved are key to the UK Criminal Justice System and to public safety. Such research stems from the work conducted in Universities by academic and research funded staff but there is also the contribution from the research project work conducted by masters and indeed undergraduate students. This level of fundamental, yet robust work can offer a significant contribution to the existing knowledge base and thereby be of use to the Criminal Justice System in answering questions that would otherwise not be investigated due to the lack of staff, time and indeed funding in the forensic research arena. Such basic forensic research, often conducted as the first piece of significant, independent research by an undergraduate or a masters level student is now being viewed by forensic practitioners and legal advocates to be a previously unmined resource of information of appropriate quality to be of use.

\section{Conclusions}

Looking forward, it is clear that forensic science educators and practitioner trainers have to adapt to the changing landscape and stakeholder requirements. University students are consumers who are mainly motivated by employment prospects and, in the tough job markets of today and tomorrow, they need reassurance of employment opportunities. Forensic science degrees need to appeal simultaneously to those who want a good quality science degree that allows them to keep their employment options open; to those who want to a generalised background to forensic science; and to those 
who want to specialise in a particular field of forensic science. Universities, departments and course providers are under increased pressure to provide high quality, stimulating content that is directly relevant to practitioner and employment experience; that utilises a wide range of multimedia and advanced technology; appeals to a variety of learning types, and that doesn't break the bank. This is an enormous task and a delicate balancing act for educators that does not appear to be diminishing in the foreseeable future.

Academics, researchers and teachers need to adapt the focus of their research in line with available grants, and demonstrate that their teaching is research-led. The competing pressures of the REF and TEF mean that wholesale changes are necessary across the forensic science educational landscape.

For practitioners, there is a real need for measures to reduce bias in UK laboratories and to raise the standards of forensic science as a whole, regardless of the decision to close the FSS. A vast majority of 81 percent of New Scientist magazine survey respondents felt that more independent research was needed to overcome current weaknesses in forensic science in the UK - something many feel will now no longer get done.

Although the forensic science education sector faces significant challenges in the next decade the future is bright for forensic education with the opportunity to embrace change and to give even better services to the forensic sector in terms of training, education and research in the next decade. 


\section{References}

Wiley Encyclopaedia of Forensic Science. Jamieson A (Ed), Wiley ISBN: 9780470061589.

Dean, K. (1990) Encouraging Forensic pedagogy. National Forensic Journal, VIII (1-3 (Spring)), pp.29-36.

Forstenzer J (2016) The Teaching Excellence Framework: What's The Purpose? Available online:

http://www.crickcentre.org/wp-content/uploads/2016/01/TEFWhats-the-Purpose-booklet-Josh-Forstenzer.pdf [Accessed 03/08/16]

Geddes, L. (2012) Forensic failure: Miscarriages of justice will occur. New Scientist, 2851: pp.10-12.

Gilmore, M. (2012) Foreword. In: Live-time Forensics. Harnessing Science and Innovation for Forensic Investigation in Policing. ACPO, 4f.

Available online:

https://connect.innovateuk.org/documents/3144739/3824722/Li ve-time Forensics brochure\%28draftv6LR\%29.pdf. [Accessed 23/03/15].

House of Commons Business, Innovation and Skills Committee (2016) The Teaching Excellence Framework: Assessing quality in Higher Education Third Report of Session 2015-16. Available online: http://www.publications.parliament.uk/pa/cm201516/cmselect/cmbis 1572/572.pdf February 2016. [Accessed 28/07/16].

NUCFS (2010) Celebrating the Second Century of the School of Law. Symposium at the University of Leeds, in collaboration with the Northumbria University Centre for Forensic Science Forensic Evidence: Expertise; Ethics; and Effectiveness. 23rd July 2012, University of Leeds 
National Institute of Justice, 1999. Forensic Sciences: Review of Status and Needs, Washington DC. Available online: https://www.ncjrs.gov/pdffiles1/173412.pdf. [Accessed 02/09/15].

QAA (2012) Subject benchmark statement: Forensic science, Available online:

http://www.qaa.ac.uk/Publications/InformationAndGuidance/Pag es/Subject-benchmark-statement-forensic-science.aspx. [Accessed 18/07/16].

Quarino, L. and Brettell, T. (2009) Current issues in forensic science higher education. Analytical and Bioanalytical Chemistry, 394(8): 1987-1993.

Rankin, B. Taylor, G. and Thompson, T. (2012) Should Higher Education respond to recent changes in the forensic science marketplace? New Directions, 8: 27-32.

Silverman, B. (2011) Research and Development in Forensic Science: a Review. (Silverman Review). Available online: https://www.gov.uk/government/uploads/system/uploads/attach ment data/file/118916/forensic-science-review-report.pdf. [Accessed 14/08/16].

The Forensic Science Society (FSSoc), Component Standards: the creation of a professional body with component standards for education. Available online: http://www.forensic-sciencesociety.org.uk/Accreditation/Component [Accessed 28/04/14].

The Science and Technology Committee (2011) The Forensic Science Service. Seventh Report of Session 2010--12, Available online:

http://www.publications.parliament.uk/pa/cm201012/cmselect/c msctech/855/855.pdf. [Accessed 31/10/15]. 
Welsh, C. and Hannis, M. (2011) Are UK undergraduate Forensic Science degrees fit for purpose? Science \& Justice, 51(3): 139142. 